\section{Stigmatic Morphology of Chinese Chestnut (Castanea mollissima Blume)}

\author{
Zhuogong Shi ${ }^{1}$ and Li Xia \\ Southwest Forestry University, Forestry Resources, Bailongsi 301, Kunming, \\ Yunnan 650224, China
}

Additional index words. Chinese chestnut, cupula, fruit load, pollination, stigmatic morphology

Abstract. The stigmatic morphology of Chinese chestnut was studied with scanning electron microscopy. The stigma is typically needle-shaped with a small aperture $\approx \mathbf{5 0} \boldsymbol{\mu m}$ in diameter on the top. During late April and early May in Yunnan Province, China, stigma secretion begins and within 1 week, secretion increases quickly and completely covers the stigma aperture. In "high fruit load" trees, the stigma aperture appears larger than in "low fruit load" trees, which in turn have a larger aperture than "empty cupule" trees. Likewise, stigma secretion in female flowers on "high fruit load" trees was higher than "low fruit load" or "empty cupule" trees.

For over 4000 years, the Chinese chestnut (Castanea mollissima Blume) has been cultivated for its nuts and timber. Chestnuts remain a very important crop in Yunnan Province, Southwest China, but low yields and alternate bearing are problems for growers. The main cause of low yield is a high empty cupule and less than three nuts per cupula at harvest. Previous studies demonstrated the rate of empty cupules in many chestnut orchards, generally $10 \%$ to $20 \%$, but sometimes above $50 \%$ and occasionally as high as $90 \%$ (Bai, 1988; Shi, 2003; Shi and Stösser, 2005; Xia et al., 1989). Earlier investigations to better understand the formation mechanism of empty cupules identified the following possible causes: poor pollination and fertilization, abnormal formation of the female gametophyte, and embryo abortion (Bai, 1988; Shi and Stösser, 2005; Yuan et al., 1997). However, recent studies, especially for Chinese chestnut seedlings (Shi et al., 2002, 2003; Shi and Stösser, 2005), have clearly shown that empty cupules and hollow nuts can still be produced, although the female flowers are sufficiently pollinated.

Flower quality, the ability of a flower to develop into a fruitlet after pollination with compatible pollen during the flower's receptive period, is linked to ovule maturity and longevity and pollen receptivity at the stigmatic surface (Buzzard and Schwabe, 1995). This study focuses on stigmatic morphology and on the influence of the fruit loads on the morphological traits of the stigma in Chinese chestnut flowers.

\section{Materials and Methods}

In Yunnan Province, Southwest China, two chestnut cultivars, Zaodali and Bayon

\footnotetext{
Received for publication 8 Jan. 2010. Accepted for publication 11 Apr. 2010.

This work was partly supported by fund of science research from the Yunnan Province, China, and also by a scholarship from DAAD (German Academic Exchange Service). The supports are gratefully acknowledged.

${ }^{1}$ To whom reprint requests should be addressed; e-mail zgongshi@sina.com.
}

III, were selected at the Yiliang County Experimental Station for an experimental period lasting from 2005 and 2006. The key selection criteria was the fruit (cupule) load status of tree, in which experimental chestnut trees were classed as "high fruit load" (HFL), "low fruit load" (LFL) (selected from the local cultivar Zaodali planted in 1998), or "empty cupule trees" (ECT) as the third (selected from the cultivar Bayon III planted in 1986 as seedlings). Of the three fruit loads selected in this experiment, the "HFL" trees during the last 2 years (2003 and 2004) cropped very well with less than $5 \%$ empty cupules. In contrast, "LFL" trees had $30 \%$ to $40 \%$ empty cupules. "ECT" trees cropped with greater than $60 \%$ empty cupules. The fruit load of each treatment trees in the experimental period was not different from that in the former years (2003 and 2004). For
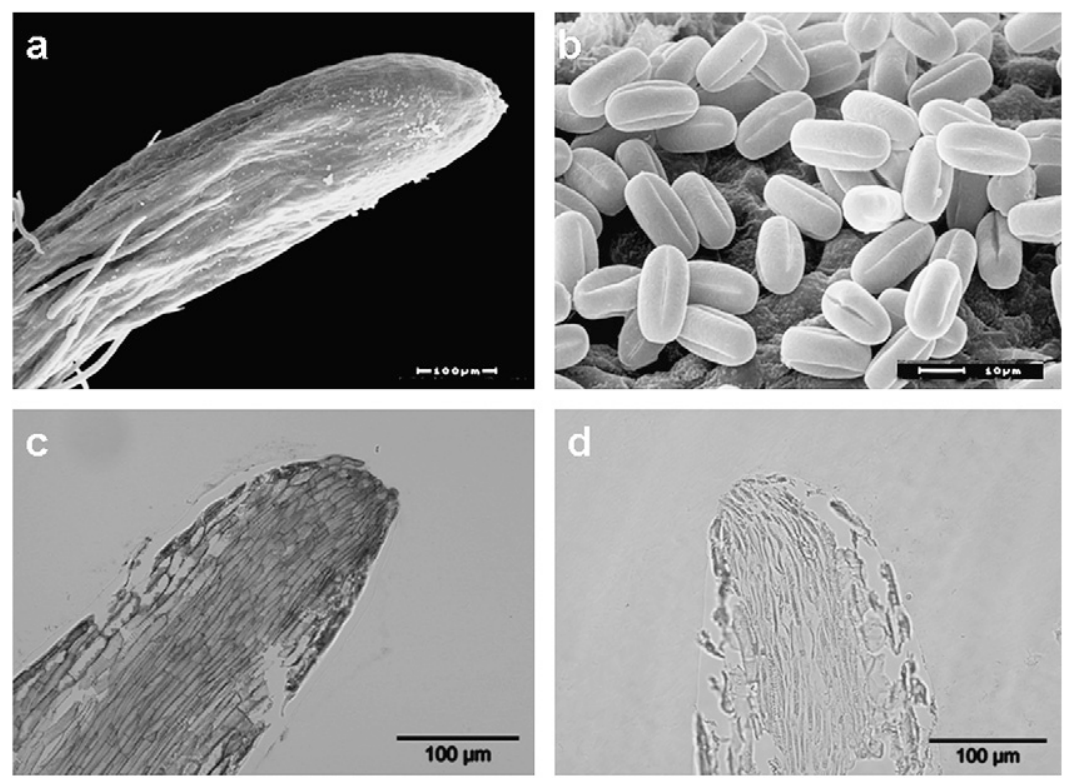

Fig. 1. Stigmatic morphology of the Chinese chestnut 'Zaodali' by scanning electron microscope and optic microscope: (A) stigma in needle shape (sampling on 8 May 2006 for HFL); (B) pollen grains on the stigma in vivo (sampling on 8 May 2006 for HFL); (C) inner tissue of stigma (sampling on 24 Apr. 2006 for HFL); (D) inner tissue of stigma (sampling on 8 May 2006 for HFL). HFL = high fruit load. each experimental treatment, three trees were selected. The sampling of three cupules (female flowers) per tree and per treatment started when the stigmas appeared in late April; later sampling was done every 7 or 8 $\mathrm{d}$ until the end of May.

Female flowers were placed immediately in microporous specimen containers and fixed in a solution made (by volume) of five parts of $37 \%$ formaldehyde, five parts of glacial acetic acid, and 90 parts of $70 \%$ ethanol (FAA solution) at ambient temperature for at least $2 \mathrm{~h}$ and then successively dehydrated in ethanol solution of the following concentrations: $70 \%$ $(1 \mathrm{~h}), 85 \%(1 \mathrm{~h})$, and 95\% (1 h) dehydrated alcohol $(1 \mathrm{~h})$. Stigmatic tissues were critical point-dried in the dryer at $40{ }^{\circ} \mathrm{C}$ for $15 \mathrm{~min}$. Specimens were mounted on an aluminum planchette with cement, gold-coated in the sputter coater (Type S150B), and examined with the AMRAY-1000B scanning electron microscope (SEM) and photographed. For each experimental treatment at each sampling date, $\approx 10$ stigmas were observed in 2005 and 2006.

Samples were fixed in a solution made of five parts of $37 \%$ formalin, five parts of propionic acid, and 90 parts of $70 \%$ ethanol. For embedding in glycolmethacrylate-methyl methacrylate (Rudell, 1967), plant tissue was first dehydrated in increasing ethanol concentrations of $70 \%, 80 \%, 90 \%$, and $96 \%$ (at least $4 \mathrm{~h}$ in each). All reagents were obtained from Merck (Darmstadt, Germany). The tissue slices were cut with a thickness of $5 \mu \mathrm{m}$ on a Reichert-Jung 2050 microtome (Leica, Bensheim, Germany)

\section{Results}

Stigmatic morphology. The stigma of the local cultivar Zaodali was observed in open 
pollination by means of SEM as seen in Figures $1 \mathrm{~A}$ and $1 \mathrm{~B}$. The stigma of Chinese chestnut is typically needle-shaped, and there is a small aperture $\approx 50 \mu \mathrm{m}$ in diameter on the top where many long secreting cells are found. With the development of female flowers, secretion spills through the aperture (Fig. $1 \mathrm{C}-\mathrm{D})$. For pollination, pollen grains usually stick together in clumps; thus, a large number of pollen grains can be found on the stigma (Fig. 1B).

Development of stigmatic morphology. For most samples, the stigma secretions were removed by the critical point-drying procedure during sample preparation, but the external features of secretion could still be observed clearly. In late April and early May, secretions began to spill out of the stigma top (Fig. 2A). A week later, secretions increased quickly and even completely covered the stigma aperture (Fig. 2B). At this time, the female flowers were strongly receptive for pollen grains, many of which could be observed on the stigma (Fig. 1B). By mid-May, pollen tubes from "HFL" trees entered into the ovary and the pollen grains with tubes could be clearly observed on the stigma (Fig. 2C). Soon after, the stigma cells stopped secreting and by the end of May secretions had dehydrated and then the stigma faded as the nuts began to develop (Fig. 2D).

Influence of the 'different fruit load' tree on stigmatic morphology. There would be differences in stigma morphology between the chestnut trees with the different fruit loads; the main differences were related to the quantity of secretion on the stigma and the aperture size of the stigmatic surface receiving the pollen grains. On average, "HFL" trees (Fig. 3A-1)
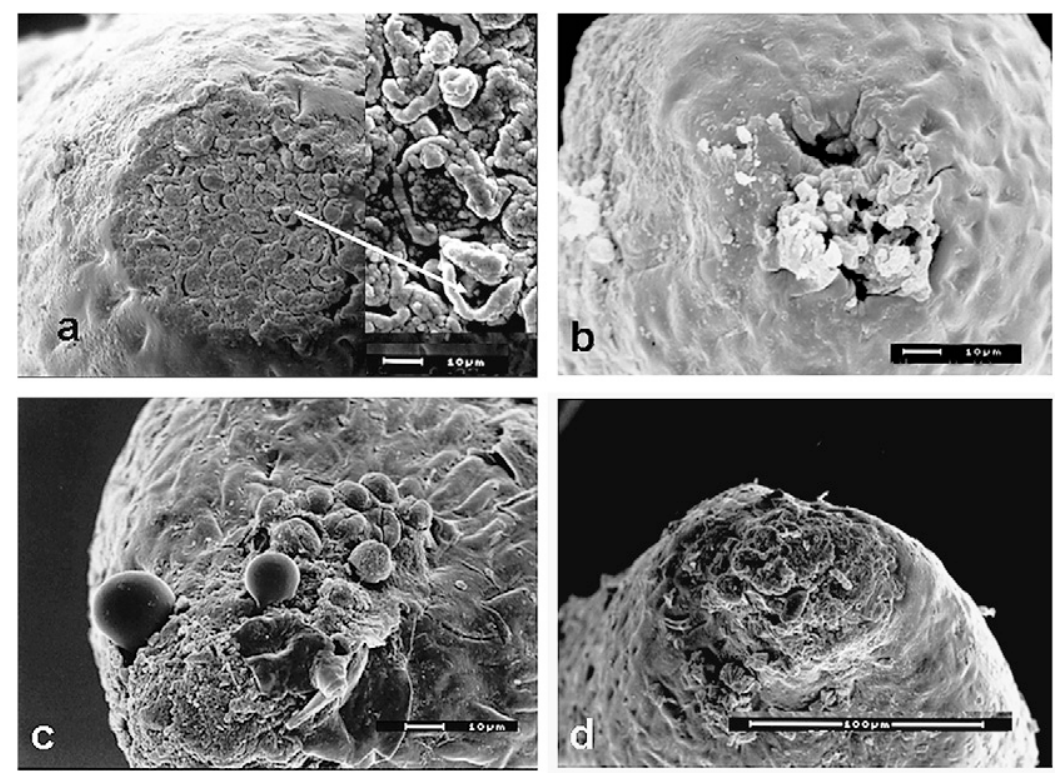

Fig. 2. Development of stigmatic morphology of the cultivar Zaodali in May by scanning electron microscope: (A) sampling on 1 May 2006 for HFL; (B) sampling on 8 May 2006 for HFL; (C) sampling on 16 May 2005 for HFL; (D) sampling on 24 May 2005 for HFL. HFL = high fruit load.
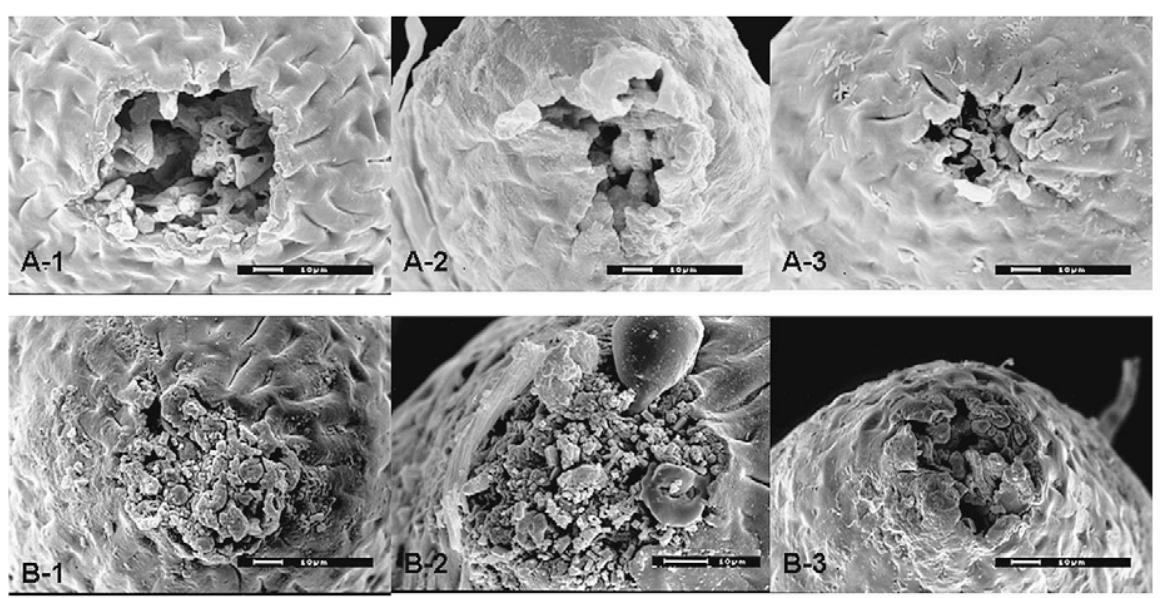

Fig. 3. Different stigmatic morphology among the fruit loads of Chinese chestnut by scanning electron microscope: (A-1) sampling on 8 May 2006 for HFL of 'Zaodali'; (A-2) sampling on 8 May 2006 for LFL of 'Zaodali'; (A-3) sampling on 8 May 2006 for ECT of 'Bayon III'; (B-1) sampling on 24 May 2006 for HFL of 'Zaodali'; (B-2) sampling on 24 May 2006 for LFL of 'Zaodali'; (B-3) sampling on 24 May 2006 for ECT of 'Bayon III'. HFL = high fruit load; = LFL = low fruit load; ECT = empty cupule trees.

had a larger aperture than "LFL" trees of the cultivar Zaodali (Fig. 3A-2), which in turn were larger than "ECT" trees (Fig. 3A-3) of the cultivar Banyou III in 2006. The quantity of secretion that covers the stigma is a vital condition for the pollen receptivity of the female flower. Likewise, secretion that remained on the stigma of the "HFL" trees (Figs. 3B-1 and Fig. 2C) was observed much more than that of "LFL" trees (Fig. 3B-2) and "ECT" samples (Fig. 3B-3).

To sum up, in "HFL" trees, ovule formation and development of the female gametophyte, germinated pollen grains on the stigma, and also the dyad-tetrad phase in the ovary could be found in mid-May (Fig. 2C), whereas these developmental steps in "LFL" trees were delayed for $\approx 1$ week. The flower development in "ECT" trees was even further delayed so that the female gametophyte was still in the dyad-tetrad phase until late May.

\section{Discussion}

Wet stigma cells have many features of gland cells and thick cytoplasm and they produce secretions during the pollination phase. Pollen receptivity is dependent on the nature of the stigmatic surface (Edlund et al., 2004; Goroo et al., 2002); moreover, the amount of pollen grains received by the stigma is influenced by its diameter and/or length (Edlund et al., 2004; Manivel et al., 2005; Yi et al., 2006). The sterile line of Medicago varia $\mathrm{cv}$. Matin had a thinner style and a smaller, sunken stigma with less secretion ( $\mathrm{Li}$ et al., 2003). In Chinese chestnut, there is a very small aperture on the top of the needleshaped stigma, and the aperture size and amount of stigma secretion would seem to be critical factors that can affect pollen receptivity of stigma. Pollen grains were usually deposited in clumps on the stigma for pollination. When the stigmatic surface is smaller, the probability for effective pollination should be correspondingly reduced.

Virgin stigmas from apple flowers on trees with a previous heavy crop load were smaller than those from previously defruited trees and flowers from previously defruited trees were more receptive to pollen at anthesis, whereas in contrast, those of previously heavily cropped trees had a shorter effective pollination period (Buzzard and Schwabe, 1995). The female flowers on chestnut had a long pollination period of over $20 \mathrm{~d}$, but the optimum pollination time was between 11 and $15 \mathrm{~d}$ after the stigma emerged from the cupule (Shi, 2003). In "LFL" trees, this optimum pollination time was delayed by 1 week, which results in a much shorter effective pollination period than in "HFL" trees of 'Zaodali'. Likewise, the development of the female gametophyte in "LFL" trees was $\approx 1$ week later than that of "HFL" trees. The later the optimum pollination time, the lower the probability that the pistil chestnut flower of the same cultivar was fertilized.

Shi and Stösser (2005) concluded that in the majority of seedling chestnut trees with a high proportion of empty cupules, genetic 
reasons were mainly responsible for causing dysplasia of the pistil so that the stigmatic aperture became smaller and female gametophyte development was delayed. Moreover, the poor nutritional status of the "LFL" trees could cause more variation of the stigma receptivity and reduce the stigma secretion and thus influence pollen germination that results in poor pollination. This might be the main reason for a higher proportion of empty cupules and hollow nuts, even when the female flowers have an adequate pollen source. Therefore, the chestnut trees should be strengthened by practices to reduce the empty cupule rate and to raise yields. Nourishment status of the chestnut trees and its fruiting may be determined on the basis of concrete stigmatic morphology and development of the female gametophyte; moreover, the corresponding cultivation technique should be taken into consideration to promote growth and development of the trees.

In this article, only qualitative results of the stigmatic characteristics among the fruit loads were determined and there was no quantitative data of the stigmatic secretion and apertures concerning the "HFL," "LFL," and "ECT" trees. This research has shown that following work should investigate further pollen tube growth in vivo and the quantitative correlation between stigmatic characteristics and fruit loads, for example, secretion and aperture of the chestnut stigma.

\section{Literature Cited}

Bai, Z. 1988. Report on the empty-cupule formation and its reducing experiment in the Chinese chestnut. Information of Forestry Science and Technology 7:5-9.

Buzzard, D. and W.W. Schwabe. 1995. Effect of previous crop load on stigmatic morphology of apple flowers. J. Amer. Soc. Hort. Sci. 120:566-570.

Edlund, A.F., R. Swanson, and D. Preuss. 2004. Pollen and stigma structure and function: The role of diversity in pollination. Plant Cell 16:84-97.

Goroo, H., H. Yoshiko, and H. Ken. 2002. Morphological studies on the development of transmitting tissues in diploid and tetraploid grape pistils. Japan. Soc. Hort. Sci. 71:8-12.

Li, H., F. Shi, and X. Cui. 2003. Observations on the morphological structure of style and stigma of male sterile line of Medica govaria Matin. cv. Acta Scientiarum Naturalium Universitatis Nei Mongol 34:671-673.

Manivel, P., K. Vinod, and K.C. Thakur. 2005. Stigma receptivity and pollination success in potato (Solanum tuberosum L.). Indian J. Genet. Plant Breed. 65:149-150.

Rudell, C.L. 1967. Embedding media for 1-2 micron sectioning. 2. hydroxyethyl methacrylate combined with 2-butoxyethanol. Stain Technol. 42:253-255.

Shi, Z. 2003. Reproduktionsbiologie der Chinesischen Esskastanie (Castanea mollissima Blume). Diss., Uni Hohenheim, Tübingen, Schwäbische Verlagsgesellschaft. p. 33-60.

Shi, Z., C. He, and H. Liu. 2002. Precocity and floral biology in Chinese chestnut (Castanea mollissima Bl.). J. Fujian College Forestry 2:137-141.

Shi, Z., C. He, and H. Tang. 2003. Study on precocity of the Chinese chestnut in Yunnan. Nonwood Forestry Res. 21:11-16.

Shi, Z. and R. Stösser. 2005. Reproductive biology of Chinese chestnut (Castanea mollissima Blume). Europ. J. Hort. Sci. 70:96-103.

Xia, R., S. Peng, and M. Ma. 1989. Study on factors effecting empty cupule formation of Chinese chestnut (Castanea mollissima Blume). I. Effects of pollination and fertilization on empty cupule formation of Chinese chestnut. J. Huazhong Agr. Univ. 8:242-247.

Yi, W.G., E. Laws, and D. Mccoy. 2006. Stigma development and receptivity in almond (Prunus dulcis). Ann. Bot. (Lond.) 97:57-63.

Yuan, Y., G. Du, and Z. Xie. 1997. Change of main nutritional substances of empty cupule occurrence in chestnut. J. Wuhan Bot. Res. 15:243-247. 